\title{
MOF-Mediated Synthesis of Supported Fe-doped Pd Nanoparticles under Mild Conditions for Magnetically Recoverable Catalysis
}

Mohanad D. Darawsheh,${ }^{\text {a† }}$ Jaime Mazarío, ${ }^{\text {b }}$ Christian W. Lopes, ${ }^{\mathrm{c}}$ Mónica Giménez-Marqués, ${ }^{\mathrm{a}}$ Marcelo E. Domine, ${ }^{\mathrm{b}}$ Debora M. Meira, ${ }^{\mathrm{d}, \mathrm{e}}$ Jordan Martínez, ${ }^{\mathrm{b}}$ Guillermo Mínguez Espallargas ${ }^{* a}$ and Pascual Oña-Burgos ${ }^{* b, f}$

a) Instituto de Ciencia Molecular (ICMol), Universidad de Valencia, c/Catedrático José Beltrán, 2, 46980 Paterna, Spain.

b) Instituto de Tecnología Química, Universitat Politècnica de València-Consejo Superior de Investigaciones Cientificas (UPV-CSIC), Avda. de los Naranjos s/n, 46022 Valencia, Spain.

c) Laboratory of Reactivity and Catalysis - Institute of Chemistry, Universidade Federal do Rio Grande do Sul, 91501-970 Porto Alegre, Brazil.

d)CLS@APS sector 20, Advanced Photon Source, Argonne National Laboratory, 9700 S. Cass Avenue, Lemont, IL 60439, USA.

e) Canadian Light Source Inc., 44 Innovation Boulevard, Saskatoon, SK S7N 2V3, Canada.

f) Department of Chemistry and Physics, Research Centre CIAIMBITAL, University of Almería, Ctra. Sacramento, s/n, Almería, E-04120, Spain.

\footnotetext{
Abstract

MOF-driven synthesis is considered as a promising alternative for the development of new catalytic materials with well-designed active sites. This synthetic approach is used here to gradually transform a new bimetallic MOF, composed of $\mathrm{Pd}$ and $\mathrm{Fe}$ as metal components, via the in situ generation of aniline under mild conditions. This methodology results in a compositionally homogeneous nanocomposite formed by $\mathrm{Fe}-$ doped Pd nanoparticles and these, in turn, supported on an iron oxide-doped carbon. The nanocomposite has been fully characterized by several techniques such as IR, Raman, TEM, XPS, XAS, among others. The performance of this nanocomposite as an heterogeneous catalyst for hydrogenation of nitroarenes and nitrobenzene coupling with benzaldehyde has been evaluated, proving it to be an efficient and reusable catalyst.
} 


\section{Introduction}

Nanostructured materials and their composites have attracted a lot of attention over the last decades in catalysis, ${ }^{[1]}$ sensing, ${ }^{[2]}$ environmental ${ }^{[3]}$ and biomedical ${ }^{[4]}$ applications. Specifically, the use of nanomaterials as catalysts in organic compound synthesis is an important pathway in order to develop viable synthetic procedures in pharmaceutical and chemical industry. ${ }^{[1]}$ In this regard, supported metal nanoparticles (NPs) are highly valued due to their high activity, selectivity and the possibility to modulate their activity by controlling their size, distribution, composition and the nature of the support. ${ }^{[5]}$

However, despite the broad applicability in different areas, high-temperature reduction of metal salts or coordination compounds is still the most common way to prepare supported metal NPs. ${ }^{[6]}$ A different route to successfully control the NP size under mild conditions consists in using metal complexes of low oxidation state in combination with long-chain aliphatic amines, ${ }^{[7]}$ although it would require the use of an inert atmosphere. An alternative approach is based on the use of templates, ${ }^{[8]}$ with the precursor serving as the source of both, metal and support.

In this sense, metal-organic frameworks $(\mathrm{MOF})^{[9]}$ offer a unique scenario. These porous crystalline materials formed by metal clusters and organic linkers have been studied in the last years for numerous applications, such as gas sorption and separation, ${ }^{[10]}$ catalysis, ${ }^{[11]}$ sensing, ${ }^{[12]}$ electronic ${ }^{[13]}$ and magnetic devices, ${ }^{[14]}$ among others. Their ordered structures act as scaffolds that result in ideal candidates for self-template precursors upon thermal conversion to well-defined nanocomposites ${ }^{[15]}$ that can be used in several fields such as catalysis, ${ }^{[16]}$ electrocatalysis, ${ }^{[17]}$ and energy storage and conversion. ${ }^{[18]}$ 
An additional benefit that accompanies the use of MOFs as precursors is the possibility of preparing dispersed and homogenous multimetallic NPs, which can be easily obtained by encapsulation of metal complexes or metal NPs in the pores of the MOF prior to the thermal conversion, ${ }^{[19]}$ or by the use of core-shell MOFs. ${ }^{[20]}$ Indeed, a better control of the homogeneity of the NPs can be achieved by the use of heterometallic MOFs. Being an example of this, the preparation of Ni-Co nanoalloy from a pre-synthesized coordination polymer using temperatures over 500 ${ }^{\circ} \mathrm{C} .{ }^{[21]}$

Herein, we present the formation of a composite material based on Nanoparticles of PdFe (PdFe-NPs) under mild conditions $\left(25^{\circ} \mathrm{C}\right)$ using a heterometallic PdFe-MOF that has also been prepared under soft conditions (120 ${ }^{\circ} \mathrm{C}$ ) in a solvent-free manner. These PdFe-NPs are directly supported on nanometric $\mathrm{FeO}_{\mathrm{x}}$ homogeneously inserted into a carbon mantle, resulting in excellent catalysts for hydrogenation reactions, forming in situ and in the absence of previous treatment.

\section{Discussion and Results}

\section{Synthesis and characterization of PdFe-MOF.}

The grinding of the solid reactants $\mathrm{Fe}\left(\mathrm{NO}_{3}\right)_{3} \cdot 9 \mathrm{H}_{2} \mathrm{O}$ and the palladium metalloligand $\mathrm{PdCl}_{2}$ (PDC) $)_{2}\left(\mathrm{H}_{4} \mathrm{~L}\right.$ where PDC: pyridine-3,5-dicarboxylic acid), followed by heating at $120{ }^{\circ} \mathrm{C}$ under vacuum results in the formation, after $72 \mathrm{~h}$, of the MOF $\left[\mathrm{Fe}_{3} \mathrm{O}(\mathrm{L})_{1.5}\left(\mathrm{H}_{2} \mathrm{O}\right)_{3}\left(\mathrm{NO}_{3}\right)\right]$, hereafter denoted as PdFe-MOF. Figure 1 represents the MOF in which the $\left[\mathrm{Fe}_{3}\left(\mu_{3}-\mathrm{O}\right)\right]$ building blocks are connected with six different tetra-carboxylic acid ligands to form a 3D structure with soc topology, isoreticular to an In analogue 
recently reported by Steriotis, Trikalitis and co-workers. ${ }^{[22]}$ This solvent-free methodology, uncommon for the preparation of MOFs, has been adapted from previously reported methods ${ }^{[23]}$ and allows the formation of the $\mathrm{Fe}$ analogue, which resulted as unfruitful using the conventional synthetic route for the PdIn-MOF analogue ${ }^{[22]}$ yielding instead an Fe-2D network with no Pd in the structure. ${ }^{[24]}$ The porous nature of PdFe-MOF, as established by $\mathrm{N}_{2}$ sorption, reveals a total $\mathrm{N}_{2}$ uptake of $250 \mathrm{~cm}^{3} \cdot \mathrm{g}^{-1}$ at $77 \mathrm{~K}$ and $0.8 \mathrm{bar}$ with a calculated BET surface area of $830 \mathrm{~m}^{2} \cdot \mathrm{g}^{-1}$ for the activated material, which is consistent with those found in the isoreticular PdIn-MOF. Further characterization of the MOF includes powder X-ray diffraction, SEM, infrared spectroscopy, thermal gravimetric analysis, XPS spectroscopy, EDS and ICP elemental analysis, which confirm the homogeneity of the sample (see ESI and Figures S1-9 for a more detailed discussion).

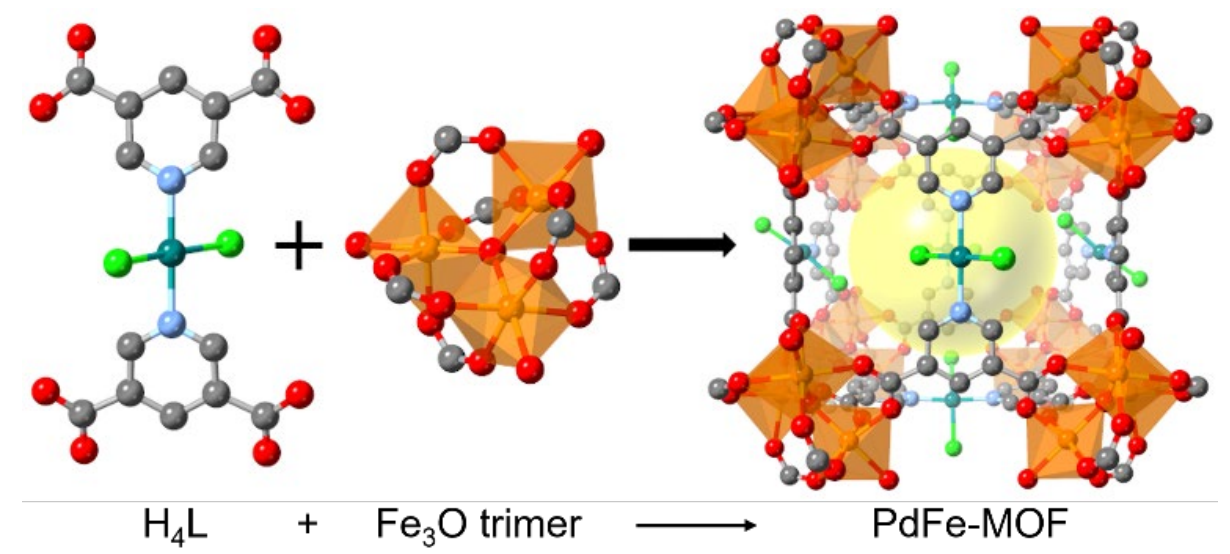

Figure 1. Schematic diagram of the metalloligand $\left(\mathrm{H}_{4} \mathrm{~L}\right)$, the oxo-centred iron carboxylate $\mathrm{SBU}$, $\left[\mathrm{Fe}_{3} \mathrm{O}(\mathrm{COO})_{6}\left(\mathrm{H}_{2} \mathrm{O}\right)_{3}\right]^{+}$and the cuboidal cage of the PdFe-MOF. Colour scheme: orange $=\mathrm{Fe}$, grey $=\mathrm{C}$, blue $=\mathrm{N}$, red $=\mathrm{O}$, dark teal $=\mathrm{Pd}$, green $=\mathrm{Cl}$, and yellow sphere represents the cavity. Hydrogen atoms are omitted for clarity. 


\section{Synthesis and characterization of PdFe-NPs}

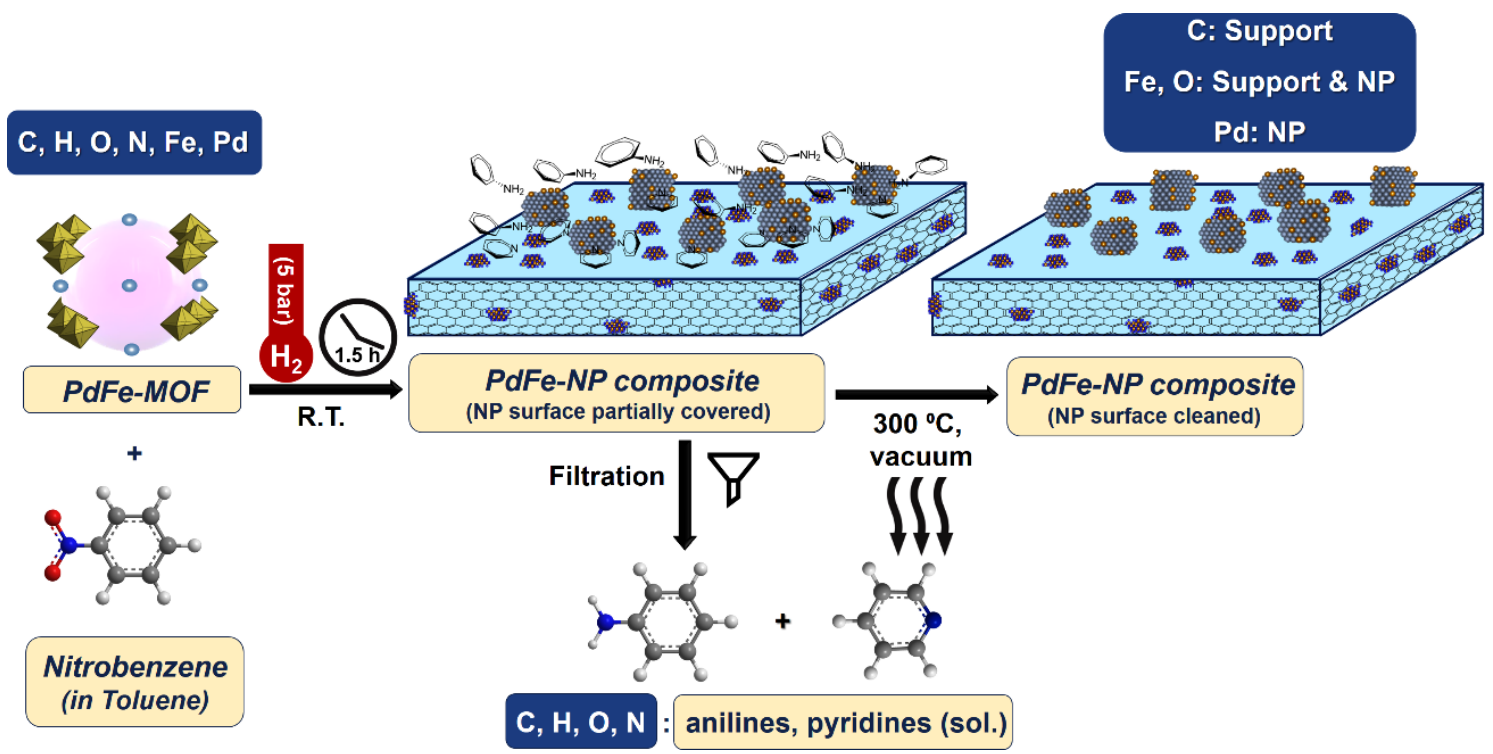

Scheme 1. Flow chart of the synthesis process to yield the nanocomposite (PdFe-NP) from the PdFe-MOF.

Preparation of the PdFe-NPs from PdFe-MOF has been achieved by adapting a previously reported procedure by Chaudret and co-workers, ${ }^{[7]}$ based on the use of an amine (aniline) in the presence of $\mathrm{H}_{2}(5$ bar) at room temperature. This modified approach consists in the in situ generation of aniline, instead of using it as a solvent, in order to provide the reaction mixture with a slow supply of the amine. As a result, the heterometallic nanocomposite (PdFe-NP) is slowly formed, therefore providing a well-controlled and reproducible material. Specifically, PdFe-MOF was mixed with toluene and nitrobenzene together with a $\mathrm{H}_{2}$ atmosphere ( 5 bar) at room temperature, and after $1.5 \mathrm{~h}$ the final nanocomposite was obtained. In this way the PdFe-MOF results in a nanocomposite (PdFe-NP) comprising both, metallic nanoparticles and a carbonaceous support, whose true nature will be thoroughly discussed over the next pages. For comparison purposes, the nanocomposite using the standard approach described by Chaudret ${ }^{[7]}$ was also 
prepared together with the traditional high temperature methodology based on thermal treatment of the $\mathrm{MOF}\left(500^{\circ} \mathrm{C}\right)$ with a $\mathrm{H}_{2}$ flow in a fixed bed reactor (see Supporting Section, Figure S11). ${ }^{[25]}$ The main materials prepared in this work are summarized in Table 1.
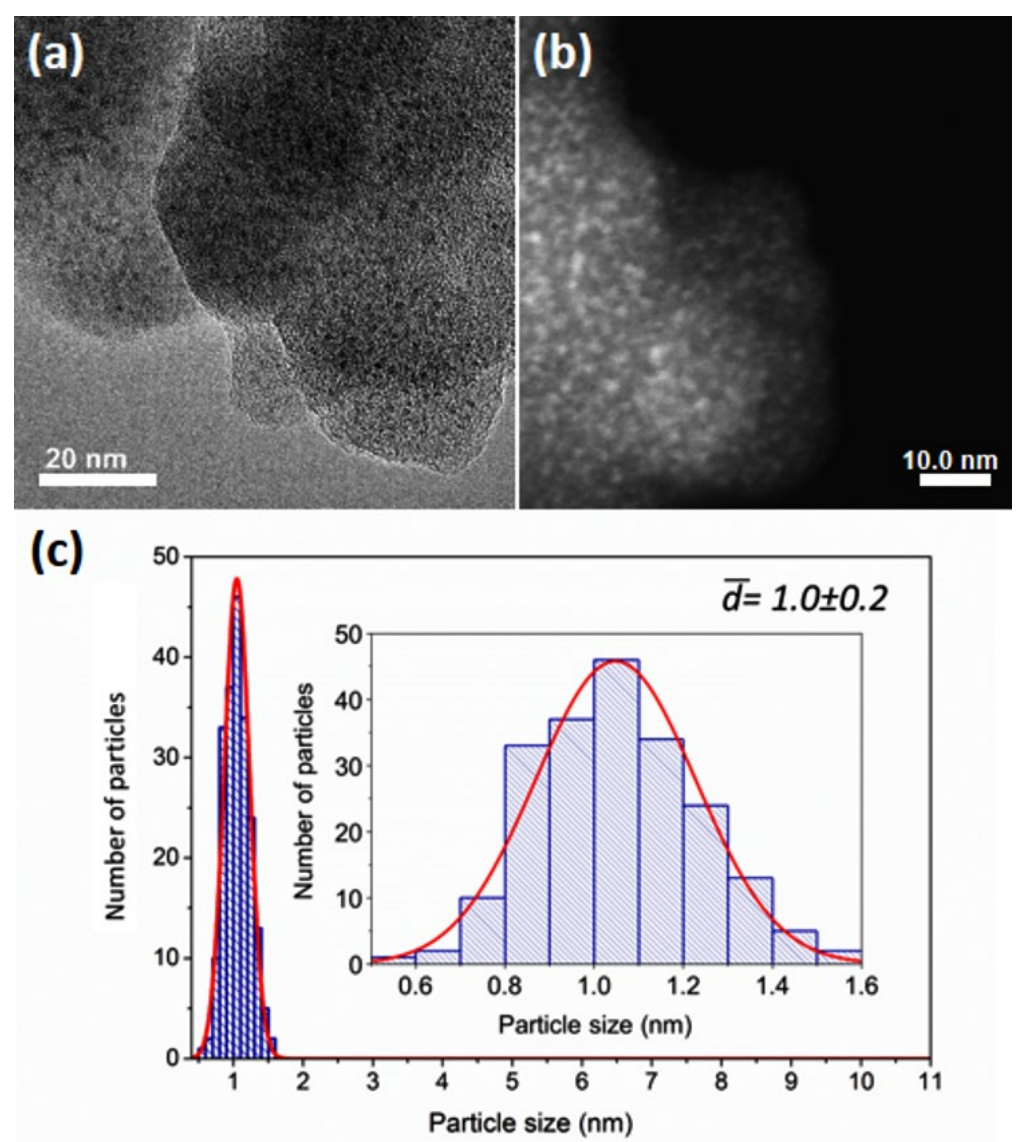

Figure 2. (a) TEM (b) STEM micrographs and (c) particle size distributions of PdFe-NP.

Electronic microscopy techniques reveal that the novel chemical methodology for the in situ preparation of NPs from a MOF results in ultra-small PdFe-NPs with a very narrow distribution, and an average size of 1.0 $\pm 0.2 \mathrm{~nm}$ (Figure 2), embedded in a carbonaceous support containing $\mathrm{FeO}_{\mathrm{x}}$. By HR-TEM, the obtained NPs are found to be smaller, and remarkably with a narrower distribution, than the NPs formed by the straightforward use of aniline $(2.0 \pm 1.8 \mathrm{~nm}$, Figure $\mathrm{S} 11 \mathrm{c})$ or by the thermal treatment of the MOF $(3.1 \pm 3.1 \mathrm{~nm}$, Figure S11b), and significantly smaller than other previously reported synthetic approaches based either on thermal and 
chemical decomposition of metallic precursors $(\approx 5 \mathrm{~nm})^{[26]}$ or high temperature thermal treatment methods $(\approx 10 \mathrm{~nm}) .{ }^{[25]}$ Based on that, it is clear that this novel methodology gives rise to NPs smaller than previously described. Moreover, in an attempt to clean the surface of the nanocomposite prior to its use in catalysis, different thermal treatments under vacuum were applied over PdFe-NP. It was concluded that these treatments did not to have any considerable effect as far as the nanoparticle size is concerned (see Figure S10).

Table 1. Summary of the main materials prepared.

\begin{tabular}{|c|c|c|}
\hline Material code & Description & NP size $^{\mathbf{a}}$ \\
\hline PdFe-MOF & Original MOF & - \\
\hline PdFe-NP & Chemically as-synthesized NP & $1.0 \pm 0.2$ \\
\hline PdFe-NP-300 & PdFe-NP heated for $6 \mathrm{~h}$ at $300{ }^{\circ} \mathrm{C}$ under vacuum & $1.2 \pm 0.3$ \\
\hline
\end{tabular}

a: Measured by HR-TEM by considering a minimum number of 200 particles.

The remarkably reduced size of the PdFe-NPs is consistent with a heterometallic nature of the NPs, in accordance with previous reports that show this effect on Pd-NPs upon doping with other metals. ${ }^{[27]}$ In fact, the possible presence of Pd and Fe in the NPs has been studied by electron diffraction (Figure S13), EDAX (Figures S14-16), X-ray powder diffraction (Figure 3a and S18), XPS (Figures S19-21) and XAS (Figures S2425). The interplanar distances of the electron diffraction patterns indicate the absence of undesired homometallic Pd crystalline phases (Figure 3b), which are however found with the common synthetic routes (Figure S13c). The presence of Fe in the NPs is confirmed by an EDAX punctual analysis of the isolated nanoparticles (Figure S14a). Further confirmation is provided by XRD (Figure 3a and S18b), which shows the centered cubic (fcc) pattern characteristic of Pd with a decrease in the cell parameter with respect to elemental palladium $(\mathrm{a}=3.8935(4)$ vs 3.8972$)$, in accordance with Vegard's law. ${ }^{[28]}$ 
Besides that, no impurities corresponding to metallic iron, iron oxide or palladium oxide are detected. Moreover, EDAX mapping of the composite reveals that iron is present in large amounts in the carbon support (Figure S15), confirmed by Raman spectroscopy to be $\mathrm{FeO}_{\mathrm{x}}$ (see Figure S22). However, the absence of any diffraction peak corresponding to iron oxide indicates a very small size of iron oxide in the carbonaceous support. On the contrary, the classic thermal methodology ends in the formation of bimetallic NPs together with other NPs based on metallic iron (Figure S18a). These data also indicate that mild reaction conditions result in NPs with higher homogeneity in composition.
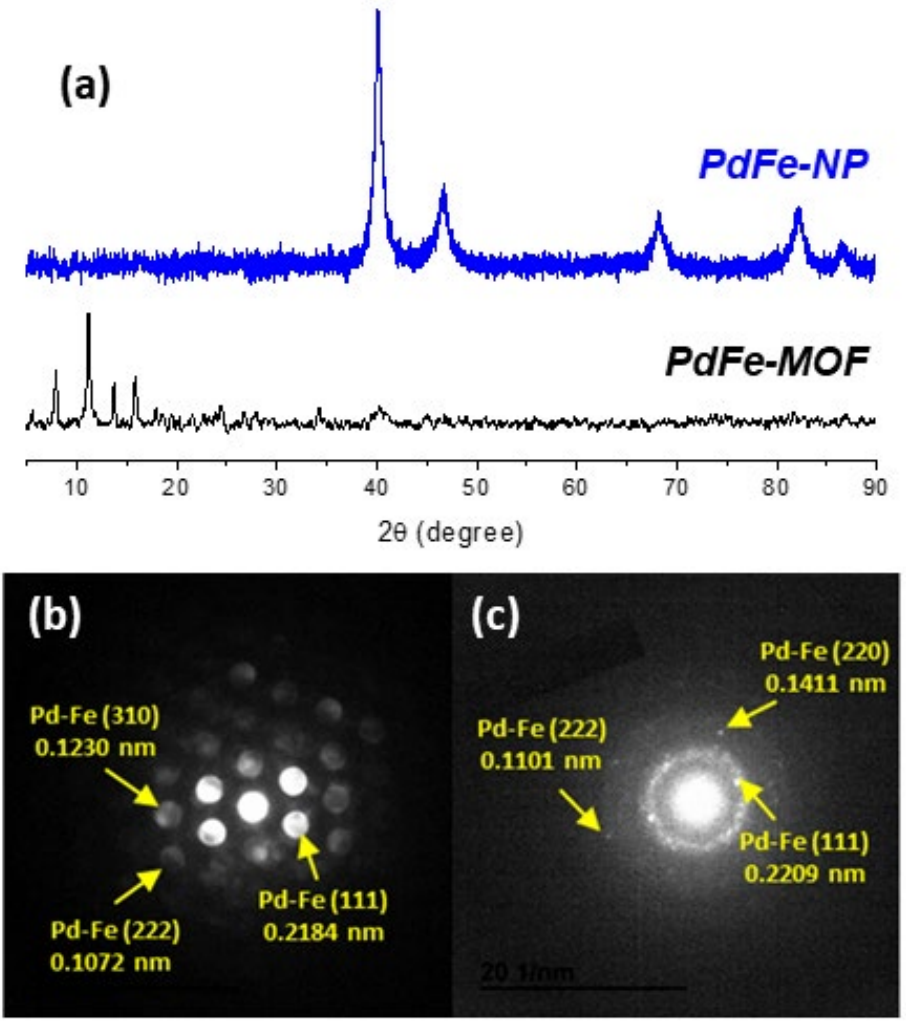

Figure 3. (a) XRD patterns for PdFe-NP and PdFe-MOF, PdFe-NP spectrum corresponds to the positions of the (111), (200), (220), (311) and (222) peaks; (b) and (c) SAED patterns of the sample PdFe-NP.

With the aim to provide further insights into the bimetallic nature of the nanoparticle composites, XPS measurements were carried out. XPS spectra interpretation and peak fitting of $\mathrm{Fe} 2 p, \mathrm{~N} 1 s, \mathrm{O} 1 s$ and $\mathrm{C} 1 s$ can be found in the Supporting Information (Figures S19-21). As can be seen in Figure 4, the Pd3d5/2 signal for the chemically prepared PdFe- 
NP is shifted towards lower binding energies than what is usually observed for $\mathrm{Pd}^{0}$. On the contrary, the NPs obtained by traditional thermal treatment barely present this shift (see Figure S21 and Table S4). This indicates that Pd is electronically richer in the chemically synthesized nanoparticles, which could be due to a charge transfer from either the $\mathrm{Fe}$ in the $\mathrm{NP}^{[29]}$ or the $\mathrm{FeO}_{\mathrm{x}}$ in the support, ${ }^{[30]}$ both situations having been previously described. However, as the nanocomposite obtained by the thermal treatment of the MOF, where no shift is seen, does not present $\mathrm{FeO}_{\mathrm{x}}$ in the support, this finding points to $\mathrm{FeO}_{\mathrm{x}}$ as the main responsible for this effect. These observations have been made taking as a reference the XPS spectra for commercial $\mathrm{Pd} @ \mathrm{C}$ (mainly $\mathrm{Pd}^{0}$, Figure 4$)$ and they could be of great significance in catalytic applications, among others.

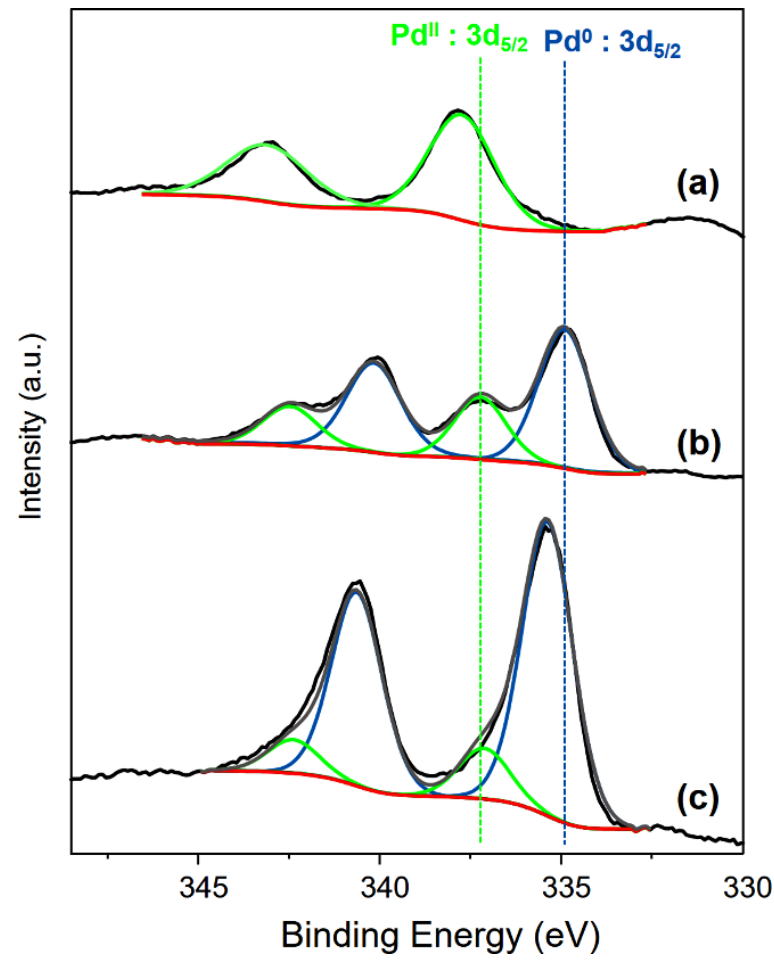

Figure 4. Pd3d XPS signal of a) PdFe-MOF, b) PdFe-NP-300, c) Pd@C (commercial).

Further details on the nature of iron species were obtained by XAS. According to both XANES and EXAFS features (Figure 5), the iron species present a structure very similar to magnetite, in good agreement with the Raman spectrum of PdFe-NP (Figure S22). The nanosized character of the $\mathrm{FeO}_{\mathrm{x}}$ is confirmed by the flattening of EXAFS signal features 
in comparison with those of $\mathrm{Fe}_{3} \mathrm{O}_{4}$ pattern, which is also reflected on the diminished $\mathrm{Fe}$ O coordination number in comparison with the bulk counterpart (Figure 5, Figure S24 and Table S5). In addition, this fitting is further improved when including a Pd contribution (Figure S25 and Table S6). The position and shape of the absorption edge in the spectrum of PdFe-NP sample indicate that Pd atoms are in the reduced state in an $f c c$ local structure. ${ }^{[31]}$ Therefore, the intensity of these oscillations points to the presence of a fraction of low coordinated atoms, causing the low amplitude of the EXAFS oscillations and, consequently, smaller nanoparticles in comparison with the bulk counterpart. However, the Pd EXAFS does not reveal this Pd-Fe interaction. This can be explained as a consequence of XAS being a bulk-sensitive technique. In this sense, the presence of some NP agglomerations (Figure S17), better detected than isolated NPs by this technique, may explain why, on average, this contribution is very small and cannot be distinguished.
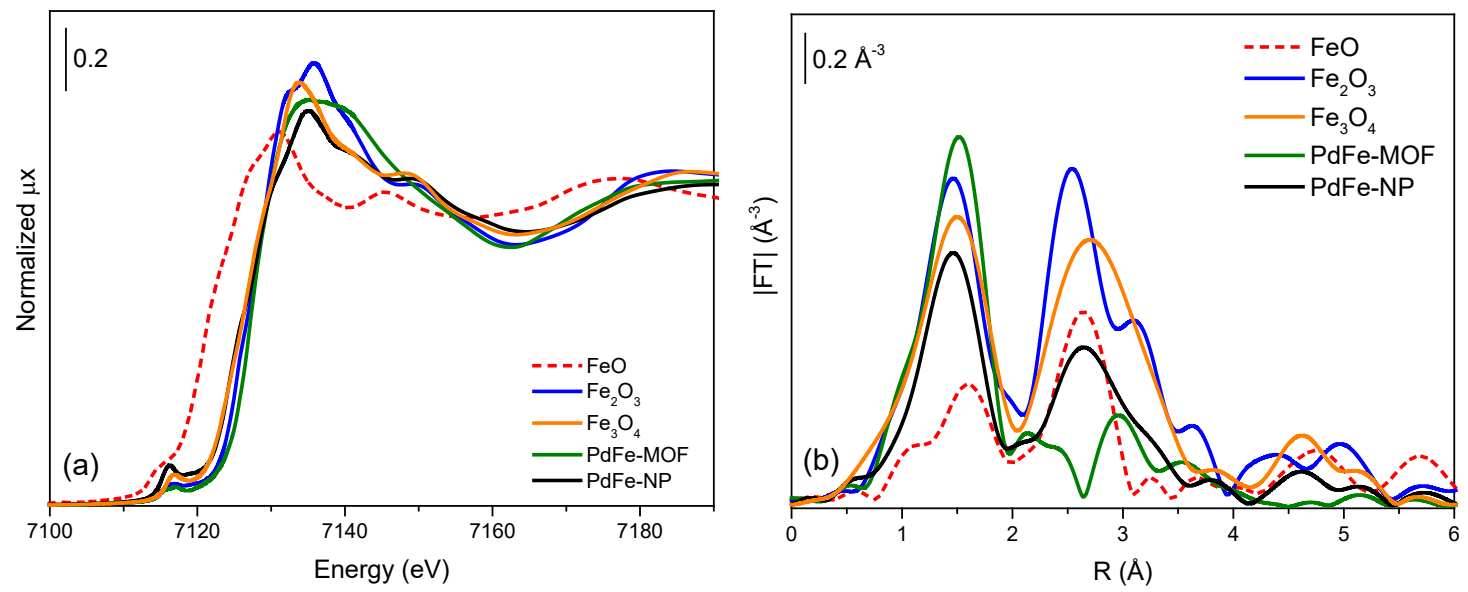

Figure 5. Normalized XANES spectra at Fe K-edge (a) and $|\mathrm{FT}|$ of the $\mathrm{k}^{2}$-weighted $\chi(\mathrm{k})$ functions (b) for PdFe-MOF, PdFe-NP and Pd-based standards.

In order to understand the mechanism of the formation of the PdFe-NP from PdFeMOF, a series of ATR-IR measurements were done upon exposing the MOF to different conditions for 30 minutes. Immersion of the MOF in toluene in the presence of 5 bar of $\mathrm{H}_{2}$ at $25^{\circ} \mathrm{C}$, or the addition of $1 \mathrm{mmol}$ of nitrobenzene, neither of them causes any major 
changes in the IR spectrum (see Figure S23), thus indicating that the PdFe-MOF remains unmodified. On the contrary, the presence of aniline significantly modifies the structure of the material, as evidenced by a shift to lower frequencies of the bands corresponding to the Fe-O bond $\left(600-650 \mathrm{~cm}^{-1}\right.$ and $\left.450-500 \mathrm{~cm}^{-1}\right)$, the disappearance of the band corresponding to the coordinated pyridine $\left(1445 \mathrm{~cm}^{-1}\right),{ }^{[32]}$ as well as by the presence of the characteristic bands of the $\mathrm{N}-\mathrm{H}$ bending associated to aniline $\left(1616\right.$ and $1556 \mathrm{~cm}^{-}$ $\left.{ }^{1}\right) .{ }^{[33]}$ Thus, aniline plays a major role in the NP formation, likely via coordination to the Pd centres, displacing the pyridine and therefore initiating the rupture of the MOF. Accordingly, the evolution of XPS for N1s also supports an effect of replacement of the pyridinic ligand from the coordination sphere of Pd by aniline (Figure S20a).

\section{Catalytic tests for nitroderivative hydrogenation}

Considering the small size and the enhanced electronic properties of PdFe-NPs, we analysed their catalytic activity in nitroarene hydrogenations (Scheme 2). Transformation of nitroarenes into anilines is of great importance, as they are one of the main building blocks for dye and pharmaceutical industries. ${ }^{[34]}$

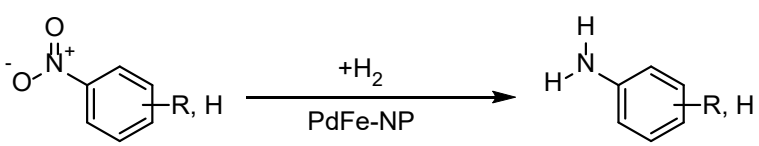

Scheme 2. Nitroarene hydrogenation.

More specifically, we investigated the capability of the prepared NPs in nitrobenzene hydrogenation. The specific activity (SA) for different Pd-based materials was calculated as the initial reaction rate (Figure 6d). Interestingly, when the Fe-doped Pd nanoparticles were chemically prepared and their surface properly cleaned after the common thermal treatment used for NP activation, i.e. $6 \mathrm{~h}$ at 300 ${ }^{\circ} \mathrm{C}$ under vacuum (PdFe-NP-300), their activity plainly surpassed that of the 
commercial Pd@C (SA = 153 vs 55, see Figure 6d). This observed improvement of the catalytic activity of our nanocomposites with respect to the commercial catalyst Pd@C could be due to the higher electronic density, observed by XPS measurements, together with the reduction in particle size (from $3 \mathrm{~nm}$ to $1 \mathrm{~nm}$, see Figures S12 and S10, respectively). ${ }^{[29-30]}$ Moreover, SA values of this bimetallic composite are ranked within the best catalysts under similar/identical reaction condition, thereby clearly improving many of the materials previously reported (see Table S7) for this particular reaction.

(a)

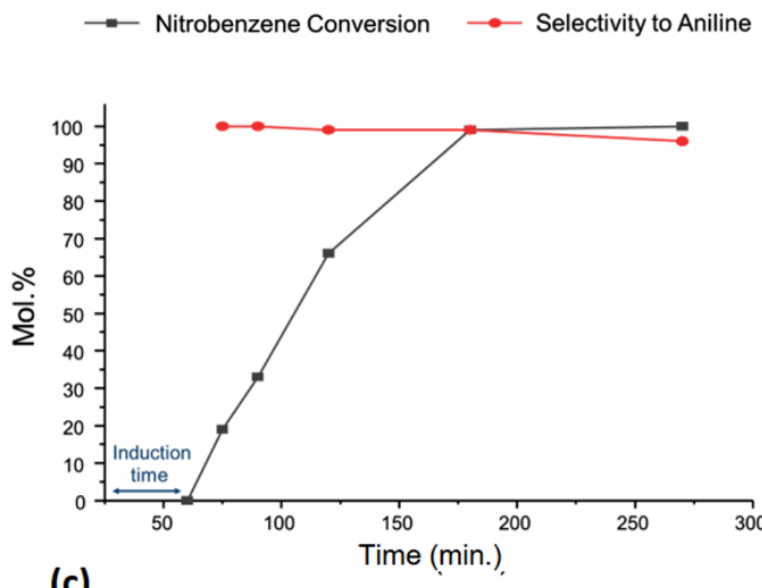

(b)

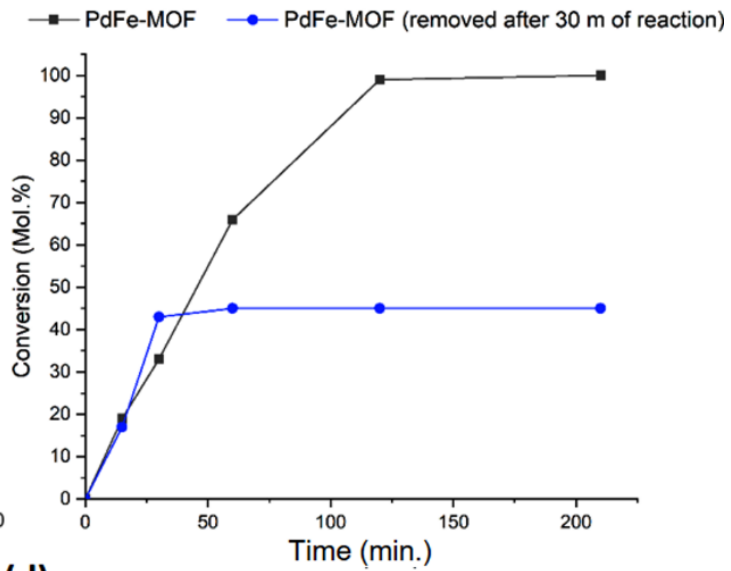

(d)

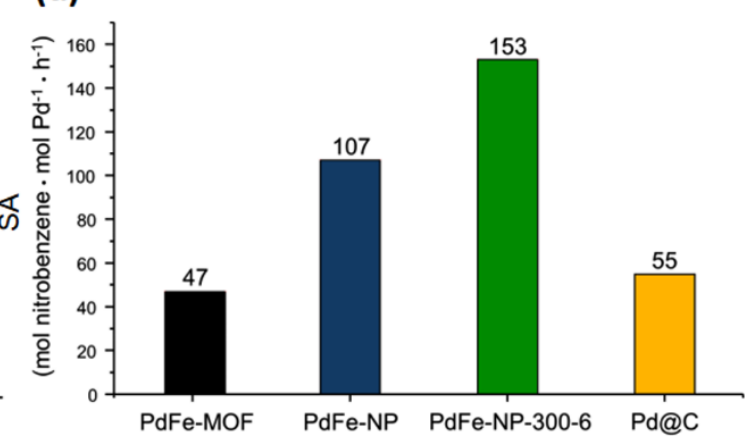

Figure 6. a) Nitrobenzene reduction with PdFe-MOF. b) Leaching test for PdFe-MOF in the nitrobenzene hydrogenation. Reaction conditions: $0.123 \mathrm{~g}$ nitrobenzene, $5 \mathrm{mg}$ PdFe-MOF, at 5 bar $\mathrm{H}_{2}$ pressure and 25 ${ }^{\circ} \mathrm{C} .1 \mathrm{~h}$ of induction. c) Reusability of PdFe-NP formed "in-situ" from PdFe-MOF. Reaction conditions: $0.123 \mathrm{~g}$ nitrobenzene, $5 \mathrm{mg}$ PdFe-MOF, at 5 bar $\mathrm{H}_{2}$ pressure and $25^{\circ} \mathrm{C}$ during $2 \mathrm{~h}$ (after $1 \mathrm{~h}$ of induction). d) Initial reaction rates (as SA) for different PdFe-based materials and comparison with a commercial catalyst. SA has been calculated after the first 30 minutes of reaction plus the corresponding induction time observed. 
However, the most remarkable results arise from the fact that the PdFe-NPs can be formed in situ. Thus, since the product of nitrobenzene hydrogenation is aniline, we hypothesised that the direct use of PdFe-MOF should also act as catalyst for this reaction, as NP formation would take place in situ. In this sense, we barely see difference when comparing the activity of PdFe-MOF against the Pd@C (SA values for PdFe-MOF and $\mathrm{Pd} @ \mathrm{C}$ are 47 and 55, respectively). Thus, the PdFe-MOF is acting as a Pd reservoir that, after an induction time, can generate active Pd species in the same reaction media, without the need of any thermal pre-treatment with $\mathrm{H}_{2}$.

Looking at the overall reaction kinetics, nitrobenzene hydrogenation takes place after $1 \mathrm{~h}$ of induction, corresponding to the already explained MOF to NP transformation, reaching yields very closed to $100 \%$ (conversion $\approx 99 \%$ and selectivity $\approx 99 \%$ ) in $2 \mathrm{~h}$ of reaction (Figure 6a). These NPs formed in situ can be reused several cycles, with a minor catalytic deactivation (Figure 6c). This small deactivation observed could be related to the deposition of organic matter on the active centres, as it is suggested by the attenuation of the Pd3d XPS signal of the material PdFe-NP (in situ formed, no thermal treatment, Figure S21) and/or to an increase in the average particle size after the catalytic process, from $1.0 \pm 0.2$ to $3.8 \pm 1.4 \mathrm{~nm}$, as it has been observed by HR-TEM (Figure S11c). Nonetheless, the loss of metals (Pd and/or Fe) from the solid to the solution during reaction could be practically discarded. In this sense, the catalyst was filtered at 30 minutes of reaction $(\mathrm{C} \leq 50 \%)$. The reaction was continued in the absence of catalyst until it reached $16 \mathrm{~h}$, and no significant changes were observed in the conversion levels of nitrobenzene. This finding meaning that the process is purely heterogeneous. (Figure 6b). With this operation, the possibility of suffering from possible desorption and reabsorption of the active species of the catalyst during the reaction was also discarded, a phenomenon that has been widely discussed in the literature when similar materials were 
used as catalysts. ${ }^{[35]}$ Moreover, the fact that the PdFe-NP were synthesized in the same reaction media used in the catalytic tests is a proof of the structural stability of the nanocomposite during the reaction and points to carbon deposition and particle size growth as the only probable reasons of deactivation. Specially the deactivation by coke deposition is in compliance with what has been stated in the literature when using Pd as the active phase for nitrobenzene hydrogenation. ${ }^{[36]}$

An additional benefit of the chemically prepared solid catalysts is the possibility of magnetically recovering them after having been used in reaction (Figures S27 and S28), an advantage which recently has started to be eagerly sought when using the synthetic approach herein described. ${ }^{[37]}$ For this purpose, the thermal treatment of the material helps to maximize the magnetic response, allowing for a successful separation after reaction. As a result, we have achieved a catalytic composite material with a higher capability to hydrogenate nitrobenzene at room temperature than that exhibited by a commercial catalyst, owing to the Fe-doped Pd-NPs, and with the additional advantage of being easily recovered with the help of a magnet, due to the $\mathrm{FeO}_{\mathrm{x}}$ species present in the support.

Table 2. Catalytic activity of "in-situ" formed PdFe-NPs when using different nitroderivatives.

\begin{tabular}{|c|c|c|c|}
\hline Reactant & Observed Product & Yield (mol.\%) $^{\mathbf{a}}$ & Induction time (h) $^{\text {Nitrobenzene }}$ \\
\hline 4-methylnitrobenzene & Aniline & 99 & 1.0 \\
\hline 4-chloronitrobenzene & 4-methylaniline & 99 & 3.0 \\
\hline Nitrostyrene & 4-chloroaniline & 73 & 4.5 \\
\hline
\end{tabular}

Reaction conditions: $0.123 \mathrm{~g}$ nitroderivative, $5 \mathrm{mg}$ PdFe-MOF, at 5 bar $\mathrm{H}_{2}$ pressure and $25^{\circ} \mathrm{C}$. ${ }^{\text {a }}$ At $2 \mathrm{~h}$ of reaction discarding the induction time in each case. Note: In the case of nitrostyrene the observed product (4-ethylaniline) is the complete hydrogenated molecule, both nitro and vinyl groups being reduced to amine and ethyl moieties, respectively.

Moreover, the PdFe-NPs can also hydrogenate other nitroarenes besides nitrobenzene such as nitrostyrene, 4-methylnitrobenzene and 4- 
chloronitrobenzene, as summarized in Table 2. Both, the induction time and the formation of the corresponding aniline, vary with the nitro-derivative used. The higher induction time observed for chloronitrobenzene with respect to methylnitrobenzene could be ascribed to the lesser reactivity of the nitro group in the presence of an electron attractor such as chloride, which can be rationalized with the Hammett parameter $\left(\sigma=-0.01\right.$ for $\mathrm{CH}_{3} ; \sigma=0.47$ for $\left.\mathrm{Cl}\right) .{ }^{[38]}$ Nitrostyrene does not follow this trend as two hydrogenations take place, with both the nitro and the $\mathrm{C}=\mathrm{C}$ being hydrogenated. The explanation for the higher induction time observed in this case is therefore more complex.

\section{Tandem reaction}

Finally, the possibility of using this new catalyst in tandem reductive amination reactions was tested (Figure 7). With this aim, the reduction reaction of nitrobenzene to aniline was coupled with the nucleophilic addition of benzaldehyde and the subsequent reduction of the formed adduct. Instead of working with an excess of benzaldehyde in the reaction mixture, slow addition of this reagent was used to decrease the rate of undesired secondary reactions resulting from benzaldehyde hydrogenation. While the one-pot reaction affords only $40 \%$ yield to the desired product (with a $60 \%$ selectivity to aniline, Fig. S26), slow addition of the carbonyl compound causes an increase of the selectivity to $75 \%$ to the benzylaniline (with a subsequent decrease of the selectivity to aniline to $20 \%$, see figure 7). Thus, this reduction of the unreacted aniline is clear proof that the benzaldehyde is not being hydrogenated so fast when lower concentrations of it are present in the reaction mixture. 


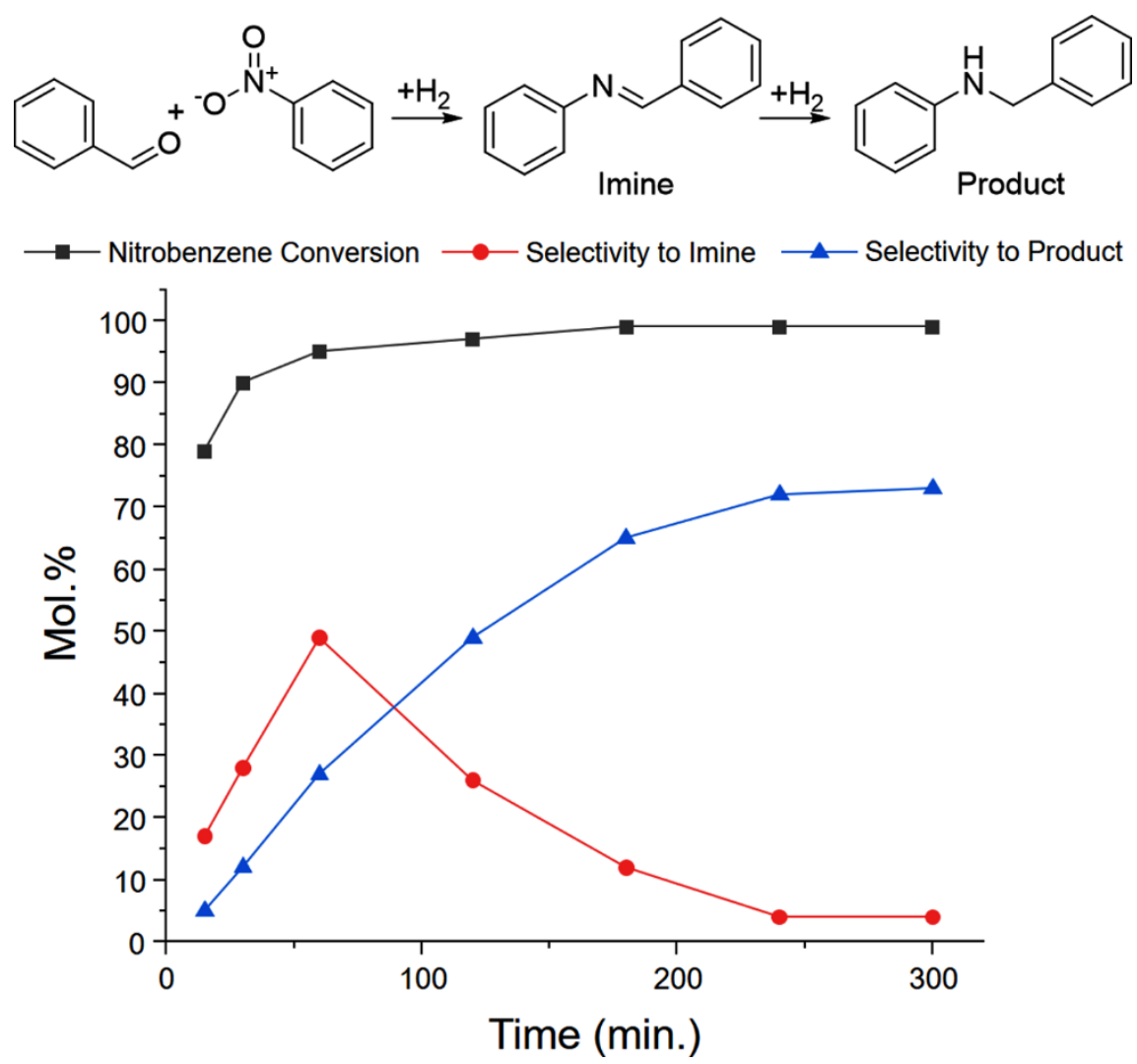

Figure 7. Coupling reaction between nitrobenzene and benzaldehyde, with slow addition of the latter. Reaction conditions: $0.123 \mathrm{~g}$ nitrobenzene, $0.106 \mathrm{~g}$ benzaldehyde (slow addition, $\mathrm{v}=102 \mu \mathrm{L} / \mathrm{h}$ ), $5 \mathrm{mg}$ PdFe@MOF, at 5 bar $\mathrm{H}_{2}$ pressure and $25{ }^{\circ} \mathrm{C}$ during $6.5 \mathrm{~h}$ (addition starts after $30 \mathrm{~min}$ of reaction, taken as $\left.\mathrm{t}_{0}\right)$. The main nitrogenated by-products detected apart from the imine was aniline $(\approx 22 \mathrm{~mol} . \%)$

\section{Conclusions}

A new family of nanocomposites based on Fe-doped Pd nanoparticles supported on an iron oxide-doped carbon has been obtained from a new bimetallic PdFeMOF. The heterometallic nanocomposite precursor PdFe-MOF is isostructural with a previously reported PdIn-MOF and has been obtained for the first time, using a solvent-free method.

A controlled decomposition of the PdFe-MOF upon in situ generation of aniline leads to the formation of ultra-small PdFe-NP, smaller and more homogeneous than the NPs obtained by conventional thermal procedures, which also provide 
other NPs based on metallic iron. In addition, PdFe-NPs obtained with our approach present excellent catalytic properties in the hydrogenation of nitroarenes, surpassing those of commercial $\mathrm{Pd} @ \mathrm{C}$ and offering the possibility of being magnetically recovered. Moreover, $\mathrm{PdFe}-\mathrm{MOF}$ can be directly used to generate the catalyst in the reaction media. In addition, compelling evidence is provided with respect to the beneficial synergy stablished when both, Fe and Pd are so close enough that they can interact with each other. The size control of the Pd nanoparticles by the presence of iron, as well as the modification of their electronic charge by the $\mathrm{FeO}_{\mathrm{x}}$ in the support, seem to be the main facts that would define the nature of this synergy.

In summary, the results obtained in this work should further strengthen the confidence in the MOF-driven synthesis as a powerful tool to prepare novel nanocomposites and catalytic systems with well-defined active sites. In particular, the methodology developed in this work could be a good starting point for the controlled transformation of MOFs having similar building units into multifunctional nanomaterials.

\section{Experimental}

\section{Synthesis of PdFe-MOF}

The metallo-ligand $\mathrm{H}_{4} \mathrm{~L}$ was prepared according to the published procedure. ${ }^{[39]}$ Concerning the MOF, a solid mixture of $\mathrm{Fe}\left(\mathrm{NO}_{3}\right)_{3} \cdot 9 \mathrm{H}_{2} \mathrm{O}(47.2 \mathrm{mg}, 0.117 \mathrm{mmol}), \mathrm{H}_{4} \mathrm{~L}(30$ $\mathrm{mg}, 0.0582 \mathrm{mmol}$ ) and benzoic acid $(3 \mathrm{mg}, 0.0246 \mathrm{mmol})$ was briefly grounded. The mixture was placed in a thin glass tube which sealed after a cycle of vacuum. The mixture was placed in a thin glass tube, sealed under vacuum and heated during $72 \mathrm{~h}$ at $120{ }^{\circ} \mathrm{C}$. 
The resulting mixture was washed with DMF and isopropanol for 1.5 days. The assynthesized MOF was activated using $\mathrm{MeOH}$ for 3 days and heated at $130^{\circ} \mathrm{C}$ for 4 hours.

\section{Nanoparticle synthesis}

As a general procedure for the in situ chemically synthesized NP, $10 \mathrm{mg}$ of PdFe-MOF were added to a solution containing $2 \mathrm{mmol}$ of nitrobenzene derivative and $2 \mathrm{~mL}$ of toluene. The system was sealed and pressurized until $5 \mathrm{H}_{2}$ bar at $25{ }^{\circ} \mathrm{C}$ under vigorous stirring for $1.5 \mathrm{~h}$. Then, the solid was filtered and repeatedly washed with $\mathrm{MeOH}$ during $24 \mathrm{~h}$ (as-synthesized PdFe-NP). In the case of thermal treatment of the as-synthesized PdFe-NP, it was placed at $300{ }^{\circ} \mathrm{C}$ during 6h under vacuum (PdFe-NP-300). For other times of activation (12 h or $48 \mathrm{~h}$ ) see Supporting Information.

For conventional thermal-treating synthesis of nanoparticles, the PdFe-MOF was activated in a tubular fix-bed reactor under a $\mathrm{H}_{2}$ flow at $500{ }^{\circ} \mathrm{C}$ during $3 \mathrm{~h}$ (see Supporting Information).

\section{Material characterization}

PdFe-MOF was characterized by XRD, IR spectroscopy, TG analysis, SEM and sorption measurements, while PdFe NPs and nanocomposites here prepared were characterized by means of chemical analysis (ICP), XRD, XPS, XAS, Raman and ATR spectroscopies, and HR-TEM (for more details see Supporting Information).

\section{Catalytic tests}

Hydrogenation reactions for nitrobenzene derivatives were carried out in a $6 \mathrm{ml}$ batch glass micro-reactor equipped with a probe for sampling and a pressure gauge for pressure measurement. For the first catalytic experiments, $0.123 \mathrm{~g}$ of 
nitrobenzene ( $1 \mathrm{mmol}), 1 \mathrm{~mL}$ of toluene and $5 \mathrm{mg}$ of solid catalyst (PdFe-MOF or PdFe-NP) were added in the same vessel. The reactor was sealed and pressurized with 5 bars of $\mathrm{H}_{2}$ at $25^{\circ} \mathrm{C}$ and maintained at $800 \mathrm{rpm}$ throughout the process. In all cases, the pressure of $\mathrm{H}_{2}$ in the system was kept constant at the selected value. Reusability tests were carried out for the in situ formed PdFe-NP. The catalyst underwent four cycles, being washed with toluene for 30 minutes in-between. The tandem reaction was performed in a similar manner albeit adding $0.106 \mathrm{~g}$ of benzaldehyde $(1 \mathrm{mmol})$ to the mixture previously described.

The progress of the reaction was followed by gas chromatography. Liquid samples $(\approx 50 \mu \mathrm{L})$ were collected at different time intervals, and then diluted in a solution of $1 \mathrm{wt} \%$ chlorobenzene (internal standard) in $\mathrm{MeOH}$. The analysis of the reaction mixtures was carried out by a 3900-Varian GC equipped with FID detector and a capillary column (HP-5, $30 \mathrm{~m}$ length). Product identification was done by GC-MS (Agilent 6890N GC System coupled with an Agilent 5973N mass detector).

In all cases, conversion $(x)$ and selectivities $(s i)$ to the different products " $i$ ", have been estimated using the formulas below at different reaction times " $t$ ", always taking nitrobenzene as a reference.

$$
\begin{gathered}
X^{t}\left(\text { mol. \%) }=\frac{n_{\text {nitrobenzene }}^{0}-n_{\text {nitrobenzene }}^{t}}{n_{\text {nitrobenzene }}^{0}} \cdot 100\right. \\
S_{i}^{t}(\text { mol. } \%)=\frac{n_{i}^{t}}{n_{\text {total } N-\text { products }}^{t}} \cdot 100
\end{gathered}
$$

SA (Specific Activity) was also calculated for nitrobenzene hydrogenation and defined as the mol of aniline produced per mol of Pd present in the catalyst per time. Finally, carbon balances were estimated for each reaction with respect to 
nitrobenzene, considering the total amount of products detected by GC analysis along with the remnant nitrobenzene.

$$
\begin{gathered}
\mathrm{SA}=\frac{n_{\text {aniline }}^{t}}{n_{P d}^{0} \cdot r \cdot t i m e} \\
C B(\mathrm{~mol} . \%)=\frac{\left[\left(n_{\text {nitrobenzene }}^{0}-n_{\text {nitrobenzene }}^{f}\right) \cdot 6 C \text { atoms }\right]+\sum\left(n_{\text {product }}^{f} \cdot X C \text { atoms }\right)}{n_{\text {nitrobenzene }}^{0} \cdot 6 C \text { atoms }} \cdot 100
\end{gathered}
$$

\section{Associated Content}

\section{Supporting Information.}

The following files are available free of charge.

Electronic Supplementary Information (ESI) available: [General methods and materials, synthesis of PdFe-MOF, PdFe-NPs and PdFe nanocomposite, and their data characterization by XRPD, IR, TG, SEM, HRTEM, XPS, XAS and Raman].

\section{Author Information}

Corresponding Author

* G. M. E. guillermo.minguez@uv.es; P. O-B.pasoabur@itq.upv.es.

\section{Notes}

$\uparrow$ These authors contributed equally to this work.

\section{Conflicts of interest}

There are no conflicts to declare. 


\section{Acknowledgements}

This work has been supported by the European Union (ERC-2016-CoG 724681-SCAGE), by the Spanish MICINN (Structures of Excellence Severo Ochoa SEV2016-0683 and María de Maeztu MDM-2015-0538; projects CTQ2017-89528-P, CTQ2015-67592, PGC2018-097277-B-100, and RTI2018-096399-A-I00 cofinanced by FEDER). We also thank the Generalitat Valenciana (PROMETEO/2018/006 and PROMETEU/2019/066). G.M.E., and P.O.-B. thank MICINN for their "Ramón y Cajal" fellowships. M.G.-M thanks support of a fellowship from "la Caixa" Foundation (LCF/BQ/PI19/11690022). J.M. thanks MICINN for his $\mathrm{PhD}$ fellowship (CTQ2015-67592). Authors also thank the Electron Microscopy Service of Universitat Politècnica de València for their support, M.P. Romero for her assistance with TEM measurements and Prof. E. Rodríguez-Castellón for discussions on the XPS spectra interpretation. This research used resources of the Advanced Photon Source, an Office of Science User Facility operated for the U.S. Department of Energy (DOE) Office of Science by Argonne National Laboratory and was supported by the U.S. DOE under Contract No. DE-AC02-06CH11357, and the Canadian Light Source and its funding partners. 


\section{References}

[1] a) L. Liu, A. Corma, Chem. Rev. 2018, 118, 4981-5079. b) M. B. Gawande, A. Goswami, T. Asefa, H. Guo, A. Biradar, D.-L. Peng, R. Zboril, R. Varma, Chem. Soc. Rev. 2015, 44, 7540-7590. c) S. Navalon, A. Dhakshinamoorthy, M. Alvaro, H. Garcia, Catalysts. Coord. Chem. Rev. 2016, 312, 99-148.

[2] a) R.A. Potyrailo, Chem. Soc. Rev. 2017, 46, 5311-5346. b) A. Kusior, M. Synowiec, K. Zakrzewska, M. Radecka, Crystals, 2019, 9, 163. c) D. Nunes, A. Pimentel, A. Gonçalves, S. Pereira, R. Branquinho, P. Barquinha, E. Fortunato, R. Martins, Semicond. Sci. Technol. 2019, 34, 043001.

[3] a) X. Li, J. Wei, K.E. Aifantis, Y. Fan, Q. Feng, F.-Z. Cui, F. Watari, J. Biomed. Mater. Res. 2016, 104, 1285-1296. b) L. Mohammed, H.G. Gomaa, D. Ragab, J. Zhu, Particuology. 2017, 30, 1-14. c) Z. Hedayatnasab, F. Abnisa, W. M. A.W. Daud, Mater. Des. 2017, 123, 174-196.

[4] a) E. Priyadarshini, N. Pradhan, Sens. Actuators B. 2017, 238, 888-902. b) C. Santhosh, V. Velmurugan, G. Jacob, S.K. Jeong, A.N. Grace, A. Bhatnagar, Chem. Eng. J. 2016, 306, 1116-1137. c) M. Ge, C. Cao, J. Huang, S. Li, Z. Chen, K.-Q. Zhang, S. S. Al-Deyab, Y. Lai, J. Mater. Chem. A. 2016, 4, 6772-6801.

[5] B. C. Gates, Chem. Rev. 1995, 95, 511-522.

[6] a) J. Mazarío, M. P. Romero, P. Concepción, M. Chávez-Sifontes, R. A. Spanevello, M. B. Comba, A. G. Suárez, M. E. Domine, Green Chem. 2019, 21, 4769-4785. b) A. García-Ortiz, J. D. Vidal, M. J. Climent, P. Concepción, A. Corma, S. Iborra, S, ACS Sus. Chem. Eng. 2019, 7, 6243-6250.c) M. Blanco, D. Mosconi, C. Tubaro, A. Biffis, D. Badocco, P. Pastore, M. Otyepka, A. Bakandritsos, Z. Liu, W. Ren et al, Green Chem. 2019, 21, 5238-5247.

[7] a) C. Pan, K. Pelzer, K. Philippot, B. Chaudret, F. Dassenoy, P. Lecante, M.-J. Casanove, J. Am. Chem. Soc. 2001, 123, 7584-7593. b) F. Dumestre, B. Chaudret, C. Amiens, M.-C. Fromen, M.-J. Casanove, P. Renaud, P. Zurcher, Ang. Chem. Int. Ed. 2002, 41, 4286-4289. c) F. Dumestre, B. Chaudret, C. Amiens, P. Renaud, P. Fejes, Science. 2004, 303, 821-823.

[8] A. Fukuoka, H. Araki, Y. Sakamoto, N. Sugimoto, H. Tsukada, Y. Kumai, Y. Akimoto, M. Ichikawa, Nano Lett. 2002, 2, 793-795.

[9] a) H.-C. Zhou, J. R. Long, O. M. Yaghi, Chem. Rev. 2012, 112, 673-674. b) G. Maurin, C. Serre, A. Cooper, G. Férey, Chem. Soc. Rev. 2017, 46, 3104-3107.

[10] R.-B. Lin, S. Xiang, H. Xing, W. Zhou, B. Chen, Coord. Chem. Rev. 2019, 378, 87-103.

[11] A. Dhakshinamoorthy, Z. Li, H. Garcia, Chem. Soc. Rev. 2018, 47, 8134-8172.

[12] Y. Zhang, S. Yuan, G. Day, X. Wang, X. Yang, H.-C. Zhou, Coord. Chem. Rev. 2018, 354, 28-45.

[13] I. Stassen, N. Burtch, A. Talin, P. Falcaro, M. Allendorf, R. Ameloot, Chem. Soc. Rev. 2017, 46, 3185-3241.

[14] G. M. Espallargas, E. Coronado, Chem. Soc. Rev. 2018, 47, 533-557.

[15] a) Y. V. Kaneti, J. Tang, R. R. Salunkhe, X. Jiang, A. Yu, K. C.-W. Wu, Y. Yamauchi, Adv. Mater. 2017, 29, 1604898. b) S. Dang, Q.-L Zhu, Q. Xu, Nat. Rev. Mater. 2017, 3, 1-14.

[16] a) V. P. Santos, T. A. Wezendonk, J. J. D. Jaén, A. I. Dugulan, M. A. Nasalevich, H.-U. Islam, A. Chojecki, S. Sartipi, X. Sun, A. A. Hakeem et al., Nat. Commun. 2015, 6, 1-8. b) F. R. Fortea-Pérez, M. Mon, J. Ferrando-Soria, M. Boronat, A. Leyva-Pérez, A. Corma, J. M. Herrera, D. Osadchii, J. Gascon, D. Armentano et 
al., Nat. Rev. Mater. 2017, 16, 760-766.

[17] E. Proietti, F. Jaouen, M. Lefèvre, N. Larouche, J. Tian, J. Herranz, J.-P. Dodelet, Nat. Commun. 2011, 2, 1-9.

[18] X. Cao, C. Tan, M. Sindoro, H. Zhang, Chem. Soc. Rev. 2017, 46, 2660-2677.

[19] a) D. Zhao, J.-L. Shui, L. R. Grabstanowicz, C. Chen, S. M. Commet, T. Xu, J. Lu, D.-J. Liu, Adv. Mater. 2014, 26, 1093-1097. b) T. Palaniselvam, B. P. Biswal, R. Banerjee, S. Kurungot, Chem. Eur. J. 2013, 19, 9335-9342. c) Y. Chen, S. Ji, Y. Wang, J. Dong, W. Chen, Z. Li, R. Shen, L. Zheng, Z. Zhuang, D. Wang et al., Angew. Chem. Int. Ed. 2017, 56, 6937-6941. d) Y. Deng, Y. Dong, G. Wang, K. Sun, X. Shi, L. Zheng, X.Li, S. Liao, ACS Appl. Mater. Interfaces, 2017, 9, 96999709.

[20] a) J. Zhao, X. Quan, S. Chen, Y. Liu, H. Yu, ACS Appl. Mater. Interfaces. 2017, 9, 28685-28694. b) Z. Wang, Y. Lu, Y. Yan, T. Y. P. Larissa, X. Zhang, D. Wuu, H. Zhang, Y. Yang, X. Wang, Nano Energy, 2016, 30, 368-378.

[21] J. Deng, P. Ren, D. Deng, X. Bao, Chem. Int. Ed. 2015, 54, 2100-2104.

[22] I. Bratsos, C. Tampaxis, I. Spanopoulos, N. Demitri, G. Charalambopoulou, D. Vourloumis, T. A. Steriotis, P. N. Trikalitis, Inorg. Chem. 2018, 57, 7244-7251.

[23] a) J. López-Cabrelles, M. Giménez-Marqués, G. Mínguez Espallargas, E. Coronado, Inorg. Chem. 2015, 54, 10490-10496. b) J. López-Cabrelles, S. MañasValero, I. J. Vitórica-Yrezábal, P. J.; Bereciartua, J. A. Rodríguez-Velamazán, J. C. Waerenborgh, B. J. C. Vieira, D. Davidovikj, P. G. Steeneken, H. S. J. van der Zant et al., Nat. Chem. 2018, 10, 1001-1007. c) J. López-Cabrelles, J. Romero, G. Abellán, M. Giménez-Marqués, M. Palomino, S. Valencia, F. Rey, G. Mínguez Espallargas, J. Am. Chem. Soc. 2019, 141, 7173-7180.

[24] H. S. Wang, H. F. Suo, Adv. Mater. Res. 2013, 790, 33-36.

[25] M.-H. Shao, K. Sasaki, R. R. Adzic, J. Am. Chem. Soc. 2006, 128, 3526-3527.

[26] a) L. M. Rivera Gavidia, G. García, D. Anaya, A. Querejeta, F. Alcaide, E. Pastor, App. Catal. B, 2016, 184, 12-19. b) Y. Pan, F. Zhang, K. Wu, Z. Lu, Y. Chen, Y. Zhou, Y. Tang, T. Lu, Int. J. Hydrog. Energy, 2012, 37, 2993-3000.

[27] R. Wang, S. Liao, Z. Fu, S. Ji, Electrochem. Commun. 2008, 10, 523-526.

[28] A. R. Denton, N. W. Ashcroft, Vegard's Law. Phys. Rev. A. 1991, 43, 3161-3164.

[29] L. M. Rivera Gavidia, G. García, D. Anaya, A. Querejeta, F. Alcaide, E. Pastor, Appl Catal. B, 2016, 184, 12-19.

[30] H. A. Elazab, S. Moussa, A. R. Siamaki, B. F. Gupton, M. S. El-Shall, Catal. Lett. 2017, 147, 1510-1522.

[31] A. Frenkel, Zeitschrift für Kristallographie - Cryst. Mater. 2009, 222, 605-611.

[32] M. Primet, Y. Ben Taarit, J. Phys. Chem. 1977, 81, 1317-1324.

[33] C. Huang, A. Li, L.-J. Li, Z.-S. Chao, RSC Adv. 2017, 7, 24950-24962.

[34] H. U. Blaser, U. Siegrist, H. Steiner and M. Studer, R.A. Sheldon and H. van Bekkum, Wiley-VCH, Weinheim, 2001, p.389.

[35] a) C. M. Hagen, L. Vieille-Petit, G. Laurenczy, G. Süss-Fink, R. G. Finke, Organometallics, 2005, 24, 1819-1831. b) D. B. Eremin, V. P. Ananikov, Coord. Chem. Rev. 2017, 346, 2-19.

[36] a) W. Xiang, S. Gebhardt, R. Gläser, C. Liu, Microporous Mesoporous Mater. 2020, 300, 110152. b) Y. Ou, L. Yao, Y. Li, C. Bai, R. Luque, G. Peng, J. Coloid. Inter .Sci, 2020, 570, 163-172.

[37] a) S. Diao, W. Qian, G. Luo, F. Wei, Y. Wang, Appl. Catal. A: Gen., 2005, 286, 30-35. b) P. Sangeetha, K. Shanthi, K.S. Rama Rao, B. Viswanathan, P. Selvam, Appl. Catal. A: Gen., 2009, 353, 160-165.

[38] C. Hansch, A. Leo, R. W. Taft, Chem. Rev. 1991, 91, 165-195. 
[39] I. Spanopoulos, I. Bratsos, C. Tampaxis, D. Vourloumis, E. Klontzas, G. E. Froudakis, G. Charalambopoulou, T. A. Steriotis, P. N. Trikalitis, Chem. Commun. 2016, 52, 10559-10562. 


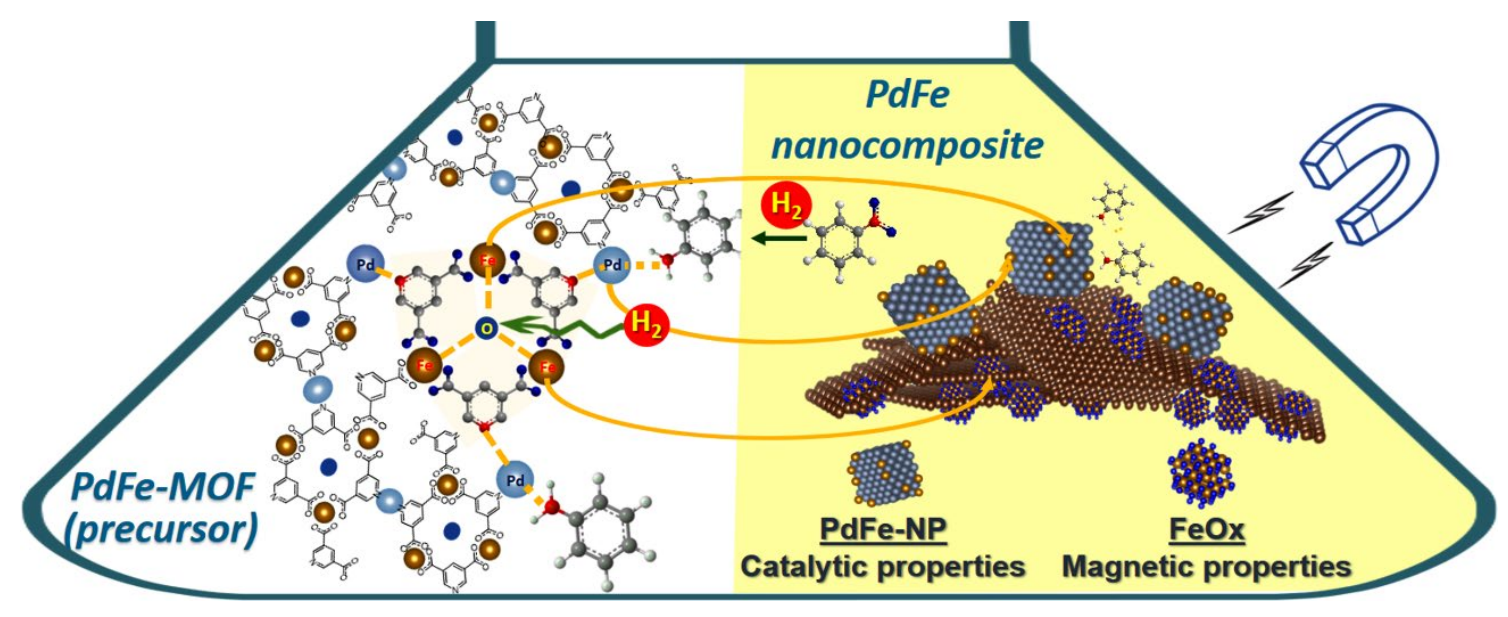

